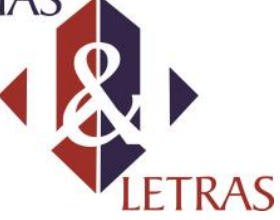

\title{
Viver Para Contar: Ficcionalização do Vivido
}

\author{
Living to Tell: fictionalization of the lived \\ Kaline Cavalheiro ${ }^{1 *}$ \\ * Universidade Estadual do Oeste do Paraná, UNIOESTE, Cascavel - PR, 38100-000 \\ e-mail:kalikonno@gmail.com
}

RESUMO: A obra de Gabriel García Márquez nos apresenta uma produção que abrange ao mesmo tempo uma escrita crítica e uma escrita criativa. Em seus textos, o autor funde diferentes estilos de escritas deixando aparecer um texto híbrido, onde o ficcional e o histórico se fundem a exemplo de autobiografia, memória, relatos, reportagens e entrevistas que revelam o sujeito escritor, a exemplo de Viver para Contar (2002). Este texto se propõe a refletir sobre a relação imbricada entre autobiografia e outros gêneros das escritas de si na obra de Gabriel García Márquez, um tecido que revela diversas camadas do real, do imaginado, da história oficial e da memória pessoal. Intenta-se apresentar o autor não apenas como um construtor da obra literária, mas como construtor de um pensamento crítico articulando obra, vida social e práticas culturais contemporâneas em conjunto com sua escrita hibrida que vai do real, ao imaginário, memorialístico, histórico, critico, entre outros.

PALAVRAS-CHAVE: Gabriel García Márquez, autobiografia, escrita de si, memória, Viver para Contar, hibridização.

ABSTRACT: The work of Gabriel García Márquez presents a production that covers, at the same time, a critical and a creative writing. In his work, the author merges different writing styles, leaving a hybrid text, where the fictional and the historical are merged with autobiography, memory, reports and interviews that reveal the subject writer, like in Living to Tell (2002). This text proposes to reflect on the overlapping relationship between autobiography and other genres of selfwriting in the work of Gabriel García Márquez, a work that reveals several layers of the real, imagined, official history and personal memory. It attempts to present the author not only as a constructor of the literary work, but as a constructor of articulating work in critical thinking, social life and contemporary cultural practices together with his hybrid writing that goes from the real to the imaginary, memorialistic, historical, critical, among others.

KEY WORDS: Gabriel García Márquez, autobiography, self-writing, memory, Living to Tell, hybridization.

\section{CONSIDERAÇÕES INICIAIS}

A vida não é a que a gente viveu, e sim a que a gente recorda, e como recorda para contá-la. (MÁRQUEZ, 2003, p. 4)

\footnotetext{
${ }^{1}$ Aluna de doutorado no Programa de Pós-Graduação em Letras da Universidade Estadual do Oeste do Paraná- Unioeste.

Volume 18

Número 40
} 


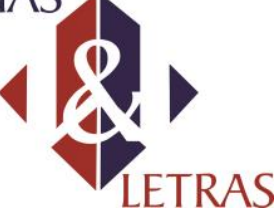

A epígrafe que abre este texto é indicial de como Gabriel Garcia Márquez inicia a sua autobiografia, deixando claro ao leitor dois pontos fundamentais, primeiro que o texto ao qual faz referência Viver para Contar $^{2}$ (2003) trata de sua autobiografia, segundo que este texto não é uma autobiografia convencional.

Em Viver para Contar, G. G. Márquez se propõe a escrever uma autobiografia e a relatar a sua vida, o principal parâmetro para se classificar um texto como autobiográfico é mantido, o autor deixa claro sua intenção, e de certa maneira realiza o seu propósito, mas ao mesmo tempo temos um autor que entra no processo de se tornar um personagem e, no caso de G. G. Márquez, o personagem/autor do livro também é escritor ficcional, consequentemente a construção de sua narrativa autobiográfica difere dos parâmetros convencionais deste gênero ao abordar aspectos narrativos que se aproximam, mais, em alguns momentos do gênero ficcional do que ao autobiográfico. G. G. Márquez não se distancia de nenhuma desses papéis, personagem/autor, criando um híbrido de si, mantendo, inclusive o tom do real maravilhoso ${ }^{3}$ que lhe é peculiar em suas obras ficcionais.

Segundo Philippe Lejeune (2008), a definição mais simples que podemos ter de um texto autobiográfico é de uma "narrativa retrospectiva em prosa que uma pessoa real faz de sua própria existência, quando focaliza sua história individual, em particular a história de sua personalidade" (LEJEUNE, 2008, p.16). Assim, seria reconhecido como autobiografia, o texto que preenche esta definição, contudo, nos parece insuficiente tal definição, diante de textos, a exemplo de Viver para Contar (2002), uma vez que a construção autobiografia é muito mais complexa do que o relato real que uma pessoa realiza de sua própria vida. Pretendemos, assim, refletir sobre o que diferencia o texto autobiográfico de outras narrativas e também, em que medida, este texto se aproxima de outros gêneros demonstrando as multifaces de uma escrita autobiográfica.

\section{REFLEXÕES SOBRE ESCRITA AUTOBIOGRÁFICA E ESCRITA DE SI}

\footnotetext{
${ }^{2}$ A data da primeira publicação de Viver para Contar é 2002. Para este texto tomamos a edição de 2003 e a edição Vivir para Contalar de 2015.

${ }^{3}$ Segundo Otto M. Carpeaux (1985). “O real maravilhoso é um patrimônio cultural da América Latina. Tudo isso ficou particularmente evidente durante minha permanência no Haiti, quando vivi em contato diário com aquilo que poderíamos chamar de Realidade Maravilhosa. [...] a cada passo encontrava a Realidade Maravilhosa. Pensava também que essa presença e vigência da Realidade Maravilhosa não era privilégio único do Haiti, senão um patrimônio de toda a América, onde ainda não se conclui, por exemplo, um inventário de cosmogonias".
}

Volume 18

Número 40 


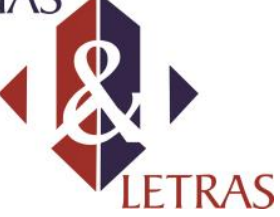

e-ISSN: 1981-4755

DOI: $10.5935 / 1981-4755.20170032$

Em seus primeiros estudos Lejeune (2008) se propõe a definir o que seria a escrita autobiográfica e em quais parâmetros ela pode acontecer. Lejeune argumenta que quando um autor se propõe a escrever uma autobiografia, este faz um pacto com o leitor e, consequentemente, ocorre um pacto do leitor com o autor diante deste gênero, o que se materializa na maneira como a obra deve ser tratada tanto em sua escrita quanto em sua leitura. Para que o pacto possa ser completo existem regras que devem ser seguidas, a exemplo de título da obra, nome do autor e estilo de escrita. Esses elementos abarcariam específicas tais como: autor e obra devem ter o mesmo nome, a escrita tem que ser em primeira pessoa, entre outras regras funcionais na construção do texto autobiográfico.

Nessa definição entram em jogo elementos pertencentes a quatro categorias diferentes, sendo elas:

Forma da linguagem: a) narrativa; b) prosa. 2 . Assunto tratado: a) vida individual; b) história de uma personalidade. 3. Situação do autor: a) identidade do autor (cujo nome remete a uma pessoa real); b) identificação do narrador. 4. Posição do narrador: a) identidade do narrador e do personagem principal; b) perspectiva retrospectiva da narrativa. É uma autobiografia toda obra que preenche ao mesmo tempo as condições indicadas em cada uma dessas categorias. Os gêneros vizinhos da autobiografia não preenchem todas essas condições. (LEJEUNE, 2008, p.16, 17).

O esquema proposto pelo autor é apenas o início da definição do que seria a escrita autobiográfica. Ao longo de seu estudo Lejeune (2008) vai aprimorando as pesquisas e abarcando outras características essenciais ao texto autobiográfico, contudo, as definições iniciais de onde o texto autobiográfico deve partir são as quatro categorias acima citadas. Posteriormente, sua pesquisa vai expandir, demonstrando outras modalidades que são construções autobiográficas e de quais maneiras diferentes escritos podem ser apresentados na perspectiva autobiográfica, como narrativa fílmica, cartas, diários, blogs, entre outros. Apesar destas variações na forma da escrita autobiográfica, o ponto inicial que é o pacto leitor/autor, sempre deve ser mantido.

A complexidade da escrita autobiográfica pode ser observada na própria construção do livro O Pacto autobiográfico. O autor observa a diversidade destas escrituras. Segundo Lejeune (2008), por muito tempo, a escrita autobiográfica foi vista apenas como uma jogada comercial, explorada pela referência do autor que tinha o nome na capa do livro. O autor explica que o caráter autobiográfico de uma narrativa o levou, por diversas vezes, a ser menosprezado, muitas vezes os escritos autobiográficos foram analisados como uma "literatura menor" e o estilo de leitura da escrita autobiográfica não Volume 18

Número 40 


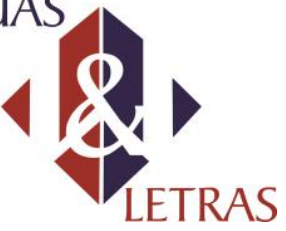

considerava a complexidade destes textos, que vão muito além de uma pessoa real falando sobre si.

O ato de rememorar é uma autoanalise da construção do sujeito autobiográfico. $\mathrm{O}$ autor de um texto autobiográfico entra num processo de ressignificação de si próprio.

$\mathrm{O}$ fato de a identidade individual, na escrita como na vida, passada pela narrativa não significa de modo algum que ela seja uma ficção. Ao me colocar por escrito, apenas prolongo aquele trabalho de criação de 'identidade narrativa', como diz Paul Ricouer, em que consiste qualquer vida. É claro que, ao tentar me ver melhor, continuo me criando, passo a limpo os rascunhos de minha identidade, e esse movimento vai provisoriamente estilizá-los ou simplificá-los. (LEJEUNE, 2008, p.121)

Denota-se daí, que durante o processo da escrita autobiográfica se ultrapassa a relação entre primeira e terceira pessoa, a autobiografia é uma construção de conhecimento do sujeito, não apenas do leitor para com o autor, mas também do próprio autor. Assim, por meio da escrita autobiográfica o autor explora mais do que o relato fiel de sua vida, ao colocar em analise diferentes aspectos em sua constituição como sujeito. Tudo nesse processo é de extrema importância, o explicito e o implícito é essencial para analisar o autor e sua obra. Sendo importante pensarmos em como se dá o processo desta escrita. Para tal, precisamos pensar na construção da memória do autor. Como o trabalho com a memória é explorado na escrita autobiográfica e como ele é transportado para o papel, nos voltamos, então, a um dos primeiros textos que demonstram a relação entre memória e escrita As Confissões de Santo Agostinho.

Em suas confissões, Agostinho relata os processos de construção de sua própria fé, contudo, ao iniciar esse processo de autoanalise ele acaba realizando não apenas um relato confessional, mas uma descrição da própria vida.

Quando poderei eu descrever, com a língua de minha pena, enumerar todas as vossas solicitações, terrores, consolações e incitamentos com que me introduzistes a pregar a vossa palavra e distribuir a vossa doutrina ao vosso povo? Mesmo que fosse capaz de as enunciar por ordem, cada gota de tempo me é preciosas. Desde menino que anseio ardentemente meditar a vossa lei, e nela confessar-Vos a minha ciência e imperícia, os primeiros alvores da iluminação da minha alma e os restos das minhas trevas, até que a minha fraqueza seja absorvida pela vossa fortaleza. (AGOSTINHO, 1987, p.209)

É importante observar que Agostinho não está falando de si no sentido autobiográfico de registro de sua vida, mas no aspecto espiritual, ou seja, na busca de conhecimento. Ao escrever suas confissões, Agostinho está buscando não apenas uma 


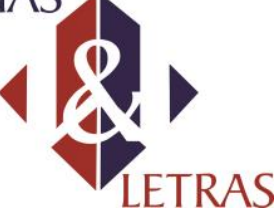

e-ISSN: 1981-4755

DOI: $10.5935 / 1981-4755.20170032$

maneira de relatar os seus ensinamentos, mas também uma maneira de entender a si mesmo e a relação com a sua própria fé. Nesta perspectiva a construção de um texto como o texto de Agostinho passa pelo mesmo processo de auto significação que observamos no texto autobiográfico. Ao escrever a suas confissões, ele está se autoanalisando e aprendendo com seus ensinamentos, durante o processo da escrita ele se torna o personagem de suas confissões e maior aluno de seus ensinamentos. Segundo Diana Klinger:

As Confissões de Agostinho, que inauguram certa 'autobiografia espiritual', procedem desta exigência dogmática de apresentar ante Deus o balanço de todos os atos, pensamentos e intenções da alma. (KLINGER, 2007, p. 25)

Ao colocar no papel as suas confissões é possível que Agostinho repense sua existência e avalie suas atitudes como um ato de reflexão de sua alma. A escrita de si se afasta das primeiras definições colocadas por Lejeune (2008) ao se colocar no campo não linear da lembrança que recorre a memória com o intuito de análise e não apenas de relato fiel da realidade.

Santo Agostinho trabalha com a construção de si através da escrita confessional na qual, o próprio autor extrapola o parâmetro da lembrança como uma simples colocação dos fatos acontecidos. Observamos em Agostinho um dos primeiros relatos de como funciona a memória no qual o autor escolhe quais pontos de sua existência devem ser relatados e, o mais importante, como devem ser relatados. $\mathrm{O}$ ato da lembrança em si torna-se de extrema importância, pois não é mais apenas uma relação entre o fato e o escrito, mas de como esse escrito é analisado pelo próprio autor. Para melhor compreender devemos nos deter em como funciona o processo de rememorar.

A memória não é linear e um dos principais problemas que muitas autobiografias encontram é como dar um tempo e espaço linear a algo que naturalmente não o é. A física einsteiniana comprova que essa é a essência do ser humano. As ondas gravitacionais são basicamente feixes de energia que distorcem o tecido do espaçotempo, o conjunto de quatro dimensões formado por tempo e espaço tridimensional. $\mathrm{O}$ nosso tempo não é um ponto fixo numa linha temporal, mas ondas que se movem e poderiam, teoricamente, ser rompidas pelas leis da física. Este ponto ainda é teórico para o mundo dos físicos, mas nas conexões realizadas em nosso cérebro e na literatura, ao embarcar no campo da memória, o rompimento é facilmente realizado. O relembrar se aproxima muito da teoria da física, ao fazermos o exercício de rememorar não temos um 


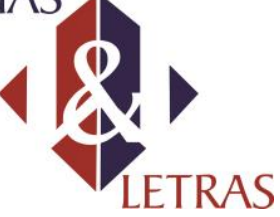

e-ISSN: 1981-4755

DOI: $10.5935 / 1981-4755.20170032$

ponto de início, meio e fim como gostamos de imaginar. A memória é fluida, segue as ondas das emoções e está diretamente ligando a maneira como nos lembramos de determinados eventos.

A tentativa de dar forma a essa fluidez do tempo e da memória é o processo que entra o autor ao se propor uma escrita autobiográfica. Nesta tentativa ainda o autor deve lidar com o referencial histórico do momento de sua escrita, neste ponto nos voltamos para as escritas de si. Ao refletir sobre a escrita de si, Klinger observa como desde a antiguidade as escritas têm um aspecto muito mais significativo do que apenas o retrato de uma pessoa.

Foucault mostra de que forma a escrita de si não é apenas um registro do eu, mas - desde a Antiguidade clássica até hoje, passando pelo cristianismo da Idade Média - constitui o próprio sujeito, performa a noção de indivíduo. O discurso autobiográfico, que se constitui na modernidade em continuidade com esse paradigma, como exacerbação do individualismo burguês, será o pano de fundo sobre o qual se constrói e, ao mesmo tempo, se destaca o discurso da autoficção. (KLINGER, 2007, p.22)

A realização da escrita de si é um processo de construção do próprio sujeito. Ao escrever sobre nós, passamos por um percurso que envolve nossa memória pessoal, analisada de um ponto, no futuro, no qual os fatos não podem mais ser alterados, mas podem ser analisados. A maneira como esta memória é narrada revela muito mais sobre o nosso eu atual do que sobre o nosso eu do passado. Assim, o relato da escrita de si está diretamente ligado à construção de sujeito e consequentemente ao momento histórico observado pelo sujeito que escreve.

As escritas de si são parte da construção de nossa história e são essenciais para entender a sociedade e a história. Elas marcam não apenas o relato oficial da história, mas as construções sociais de cada sujeito. Neste aspecto, o livro Viver para Contar (2003), de G. G. Márquez também se afasta da escrita autobiográfica, tomando um caráter literário, ao abordar a memória do autor que, analisa a construção de sua existência, ficando no limiar entre a escrita de si e o texto autobiográfico.

Na obra de G. G. Márquez observamos que elementos da esfera social, da história e da própria vida do autor estão de tal maneira fundidos que apenas em uma construção híbrida, seria possível elaborar.

La del 27 de julio de 1950, en la casa e la Negra Eufemia, tuvo un cierto valor histórico en mi vida de escritor. No sé por qué buena causa la dueña había ordenado un sancocho épico de cuatro carnes, y los 
alcaravanes alborotados por los olores montaraces extremaron los chillidos alrededor del fogón. Un cliente frenético agarró un alcaraván por el cuello y lo echó vivo en la olla hirviendo. El animal alcanzó apenas a lanzar un aullido de dolor con un aletazo final y se hundió en los profundos infiernos. El asesino bárbaro trató de agarrar otro, pero la Negra Eufemia estaba ya levantada del trono con todo su poder.

-i Quietos, carajo - gritó -, que los alcaravanes les van a sacar los ojos!

Solo a mí me importó, porque fui el único que no tuvo alma para probar el sancocho sacrílego. En vez de irme a dormir me precipité a la oficina de Crónica y escribí de un solo trazo el cuento de tres clientes de un burdel a quienes los alcaravanes les sacaron los ojos y nadie lo creyó. ${ }^{4}$ (MÁRQUEZ, 2015, p. 405, 406)

Observa-se um elemento essencial na forma como o autor trabalha o texto autobiográfico, muitas vezes, se aproxima tanto da ficção que parece impossível reconhecer suas margens, ficção? autobiografia? escrita de si? autoescrita?

A partir das reflexões entre a relação de textos autobiográficos e de escritas de si, trazemos a obra Viver para Contar (2003) de G. G. Márquez, que está classificada como uma autobiografia, contudo, a obra traz marcas da escrita de si com elaborações do ficcional, tornando-se um texto híbrido. O autor é o mesmo do título da obra, a base inicial do pacto é firmada entre o autor e leitor, mas diferentemente dos primeiro estudos definidos por Lejeune (2008), G. G. Márquez trabalha com a construção de seu próprio personagem, viajando nos campos da memória e na construção de si.

Quem é Gabriel Garcia Márquez na visão do próprio autor? Para realizar essa construção híbrida, o autor nos apresenta uma narrativa fundada no livre fluxo de consciência, a qual conduz o leitor a diferentes momentos de sua vida. $\mathrm{O}$ autor trabalha com personagens reais descritos como criaturas fantásticas, embaralhando fatos de suas lembranças apresentadas ao leitor.

Mi último recuerdo de su esposa Wenefrida fue el de una noche de grandes lluvias en que la exorcizó una hechicera. No era una bruja convencional sino una mujer simpática, bien vestida a la moda, que

\footnotetext{
${ }^{4}$ A do dia 27 de julho de 1950, na casa de festas da Negra Eufemia, teve certo valor histórico em minha vida de escritor. Não sei qual terá sido a boa razão que levou a dona da casa a encomendar um sancocho épico de quatro carnes, e ao redor do fogão os alcaravões, alvoroçados pelos odores indomáveis, elevaram seus chiados ao máximo. Um cliente frenético agarrou um pelo pescoço e atirou-o ainda vivo dentro do caldeirão. $\mathrm{O}$ bicho mal conseguiu lançar um uivo de dor com um derradeiro agitar de asas, e afundou nos infernos profundos. O assassino bárvaro tratou de agarrar outro, mas a Negra Eufemia já tinha se levantado de seu trono com todo seu poder.

— Quietos, caralho! - gritou -, esses bichos vão acabar arrancando seus olhos!

Fui o único a se importar, porque também fui o único que não teve alma para provar o sancocho sacrílego. Em vez de ir dormir, me precipitei para redação de Crónica e escrevi num só fôlego o conto de três cliente de um bordel, cujos olhos são arrancados pelos alcaravões, e ninguém acreditou na história. (MÁRQUEZ, 2003, p. 363, 364)
}

Volume 18

Número 40 


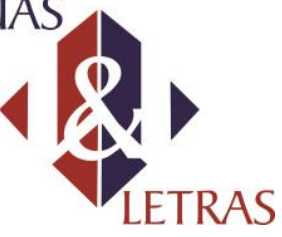

espantaba con un ramo de ortigas los malos humores del cuerpo mientras cantaba un conjuro como una canción de cuna. De pronto, Nana se retorció con una convulsión profunda, y un pájaro del tamaño de un pollo y plumas tornasoladas escapó de entre las sábanas. La mujer lo atrapó en el aire con un zarpazo maestro y lo envolvió en un trapo negro que llevaba preparado. Ordenó encender una hoguera en el traspatio, y sin ninguna ceremonia arrojó el pájaro entre las llamas. Pero Nana no se repuso de sus males. ${ }^{5}$ (MÁRQUEZ, 2015, p. 85, 86)

G. G. Marquéz também deixa claro desde a epígrafe, citada no início deste texto, que algumas partes de sua obra podem não retratar a realidade da maneira como outras pessoas se lembram, mas a sua versão da realidade. A maneira como G. G. Marquéz trabalha com suas memórias é uma construção temporal de seu próprio Eu.

Ni mi madre ni yo, por supuesto, hubiéramos podido imaginar siquiera que aquel cándido paseo de sólo dos días iba a ser tan determinante para mí, que las más larga y diligente de las vidas no me alcanzaría para acabar de contarlo. Ahora, con más de setenta y cinco años bien medidos, sé que fue la decisión más importante de cuantas tuve que tomar en mi carrera de escritor. Es decir: en toda mi vida. ${ }^{6}$ (MÁRQUEZ, 2015, p. 11)

Viver para Contar (2003), se aproxima das escritas sobre si, passa a ser mais do que apenas um pacto de narrativa que reflete a absoluta verdade como o texto autobiográfico, tomando um caráter de construção do sujeito. O próprio Lejeune (2008) coloca que o termo "pacto" se tornou muito forte para definir este tipo de escrita. $\mathrm{Na}$ contemporaneidade observam-se cada vez mais livros como o de G. G. Márquez, no qual o campo da autobiografia e da escrita de si se fundem, fazendo aparecer um texto híbrido,

\footnotetext{
${ }^{5}$ Minha última lembrança de sua esposa Wenefrida foi a da noite de grandes chuvas em que uma feiticeira a exorcizou. Não era uma bruxa convencional e sim uma mulher simpática, bem vestida e na moda, que espantava com um ramo de urtigas os maus humores do corpo enquanto catava um esconjuro que parecia uma canção de ninar. De repente, Nana se retorceu com uma convulsão profunda, e um pássaro do tamanho de um frango e de penas furta-cor escapou do meio dos lençóis. A mulher agarrou-o no ar com um bote de mestre e envolveu-o num trapo negro, que já estava preparado. Mandou acender uma fogueira no quintal dos fundos, e sem nenhuma cerimônia atirou o pássaro no meio das chamas. Mas Nana não se recompôs de seus males. (MÁRQUEZ, 2003, p. 75)

${ }^{6} \mathrm{Nem}$ minha mãe nem eu, é claro, teríamos podido nem mesmo imaginar que aquele cândido passeio de dois únicos dias seria tão determinante para mim a mais longa e diligente de todas as vidas não me bastaria para acabar de conta-lo. Agora, com mais de setenta e cinco anos bem pesados, sei que foi a decisão mais importante de todas as que tive que tomar na minha carreira de escritor. Ou seja: em toda a minha vida. (MÁRQUEZ, 2003, p. 9)
}

Volume 18

Número 40 


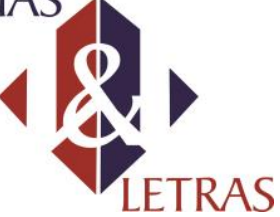

e-ISSN: 1981-4755

DOI: $10.5935 / 1981-4755.20170032$

com a fusão de dois, ou mais estilos de escritas. Assim, trataremos Viver para contar (2003), ressaltando esta hibridização de escrita e o referenciaremos como "autoescrita"7.

Desde a primeira definição de texto autobiográfico proposto por Lejeune, passando por diversas leituras de textos formadores deste estilo, percebemos o quão complexa é a construção de uma obra autobiográfica. Em Viver para Contar (2003), observamos essa complexidade durante toda a narrativa. A princípio, é possível verificar que o formato da autobiografia de G. G. Márquez diferencia-se do que o leitor está habituado a entender como uma autobiografia; a narrativa segue um fluxo de consciência que transporta o leitor durante diferentes épocas da vida do autor. Durante os relatos, temos pontos da vida de G. G. Márquez que parecem parte do real maravilhoso pelo estilo da narrativa.

Para mí era un lugar histórico: a mis tres o cuatros años, en el curso de mi primer viaje a Barranquilha, el abuelo me había llevado de la mano a través de aquel yermo ardiente, caminando deprisa y sin decirme para qué, y de pronto nos encontramos frente a una vasta extensión de aguas verdes con eructos de espuma, donde flotaba todo un mundo de gallinas ahogadas. (MÁRQUEZ, 2015, p.20)

A narrativa contém o elemento do real maravilhoso, o autor narra sentimentos que expressam mais daquele momento do que uma simples lembrança de um menino de três anos. Em diversos momentos como este o leitor se sente diante de uma obra ficcional que está sendo moldada como um relato real. $\mathrm{O}$ autor narra não apenas um momento de sua vida, mas constrói a sua relação com o avô, com a casa onde cresceu, com a cidade e seus primeiros contatos com o mundo, torna os fatos mais simples de sua vida em acontecimentos monumentais. $\mathrm{O}$ trabalho do autor com suas lembranças vão além do texto autobiográfico, como ele mesmo diz suas visões o perseguem: "hasta que conseguí exorcizarla en un cuento.” (MÁRQUEZ, 2015, p.31)9. As memorias de G. G. Márquez colocam em confluência o real e o ficcional como um simples caractere na narrativa.

G. G. Márquez coloca o leitor em um ponto de total ambiguidade, estamos lendo uma autobiografia que foi escrita pelo autor, que o título está na capa do livro, mas, ao

\footnotetext{
7 Formulação conceitual desenvolvida durante pesquisa de mestrado, a partir da leitura completa da obra do autor e de teorias sobre as escritas de si, para pensar o modus operandi da escrita de Gabriel Garcia Márquez.

${ }^{8}$ Para mim, era um lugar histórico: aos meus três ou quatro anos, durante minha primeira viagem a Barranquilha, meu avó tinha me levado pela mão através daquele imenso baldio ardente, caminhando depressa e sem me dizer para quê, e de repente nos encontramos diante de uma vasta extensão de águas verdes com golfadas de espumas, onde flutuava um mundo inteiro de galinhas afogadas. (MÁRQUEZ, 2003, p.17)

9 Até que consegui exorcizá-la em um conto. (MÁRQUEZ, 2003, p.27)
}

Volume 18

Número 40 


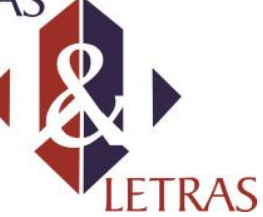

e-ISSN: 1981-4755

DOI: $10.5935 / 1981-4755.20170032$

mesmo tempo, somos apresentados a lembranças que parecem sair do mundo da fícção e percebemos como o real relatado nessa escrita de G. G. Márquez aparece no maravilhoso narrado em suas obras ficcionais e um não se sustenta sem o outro. O texto remete ao primeiro parágrafo de Cem anos de Solidão ${ }^{10}$. "Muitos anos depois, diante do pelotão de fuzilamento, o Coronel Aureliano Buendía havia de recordar aquela tarde remota em que seu pai o levou para conhecer o gelo". (MÁRQUEZ, 2003, p.7).

O momento aqui transformado em ficção aparece na autoescrita no momento que o avô de G. G. Márquez o leva para conhecer pela primeira vez o gelo quando pequeno. O autor faz confluir relatos da autobiografia a obras de ficção anteriormente escrita por ele mesmo. Nunca dando ao leitor a certeza do que é real, tal como o narrador nos diz: "El recuredo es nítido, pero no hay ninguna posibilidad de que sea certo" . (MÁRQUEZ, 2015, p.72).

O autor rompe com o pacto estabelecido por Lejeune para a autobiografia e vai além da escrita de si ao fundir o real, o histórico e o ficcional. O real e o imaginado se confundem, tornando a escrita um híbrido entre ficção, autobiografia e escrita de si. O leitor entra no mundo da memória do autor, onde fatos históricos se transformam no real maravilhoso.

A ambiguidade se instaura para o leitor, contudo, os relatos não são vistos pelo autor como uma quebra do pacto com o leitor que espera o relato real de sua vida, eles são colocados como o processo de construção de sua vida como “autor", temos, então, o processo do autor incorporando para si o personagem que ele cria de si mesmo, transformando histórias que escutou em sua infância em narrativas de caráter próprio do real maravilhoso.

Nesse processo criativo, há uma fusão e por que não dizer justaposição entre as categorias autor, personagem e narrador na confluência entre autobiografia, memória e ficção, por isso denominamos de autoescrita, sendo, justamente este modo de narrar bastante expressivo na obra de G. G. Marquéz.

Durante toda a narrativa de Viver para Contar (2003) encontramos referências a outras obras de G. G. Márquez, o que torna claro não se tratar apenas de uma questão de não cumprimento do pacto com o leitor no relato da verdade, mas que esta é a "realidade" do autor. Segundo Andrei Tarkovski.

\footnotetext{
${ }^{10}$ A data da primeira publicação de Cem anos de Solidão é de 1967. Para esta pesquisa tomamos a edição de 2003.

${ }^{11}$ A lembrança é nítida, mas não existe a menor possibilidade de ser verdadeira (MÁRQUEZ, 2003, p.64). Volume 18

Número 40
} 


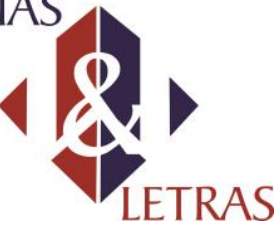

O tempo e a memória incorporam-se numa só entidade são como os dois lados de uma medalha. É por demais óbvio que, sem o Tempo, a memória também não pode existir. A memória, porém é algo tão complexo que nenhuma relação de todos os seus atributos seria capas de definir a totalidade das impressões através das quais ela nos afeta. A memória é um conceito espiritual! Se, por exemplo, alguém nos fizer um relato das suas impressões da infância, poderemos afirmar, com certeza, que temos em nossas mãos material suficiente para formar um retrato completo dessa mesma pessoa. (TARKOVISK, 1998, p.64, 65)

A autoescrita de G. G. Márquez se mostra uma construção literária que justapõe a escrita de si, o autor manipula a sua própria percepção do tempo para construir o relato pessoal. Nesse relato temos partes que parecem ficcionais em uma obra que demonstra não apenas a vida e crescimento do autor, mas a própria construção como escritor.

Encontramos aspectos que confluem com o pacto autobiográfico definido por Philippe Lejeune (2008), em conjunto com partes que rompem totalmente com o pacto.

En ésas andaba una noche de domingo en que por fin me sucedió algo que merecía contarse. Había pasado casi todo el día ventilando mis frustraciones de escritor con Gonzalo Mallarino en su casa de la avenida Chile, y cuando regresaba a la pensión en el último tranvía subió un fauno de carne y hueso en la estación de Chapinero. He dicho bien: un fauno. Noté que ninguno de los escasos pasajeros de medianoche se sorprendió de verlo, y eso me hizo pensar que era uno más de los disfrazados que los domingos vendían de todo en los parques de niños. Pero la realidad me convenció de que no podía dudar, porque su cornamenta y sus barbas eran tan montaraces como las de un chivo, hasta el punto que percibí al pasar el tufo de su pelambre. [...] la mañana siguiente ya no supe si en realidad había visto un fauno en el tranvía o si había sido una alucinación dominical. ${ }^{12}$ (MÁRQUEZ, 2015, p. 295)

A autoescrita de G. G. Márquez é uma manipulação do tempo e memória, como a teoria da física, o autor viaja por diversos momentos de suas memórias e a partir dessa viajem vai ressignificando a si mesmo, como passagens que remetem ao

\footnotetext{
${ }^{12}$ Nessas andava eu numa noite de domingo quando enfim me aconteceu uma coisa que valia a pena ser contada. Eu tinha passado quase que o dia inteiro ventilando minhas frustrações de escritor com Gonzalo Mallarino na sua casa da avenida Chile, e quando voltava para a pensão no último bonde um fauno de carne e osso subiu na estação Chapinero. O que eu falei foi isso mesmo: um fauno. Notei que nenhum dos escassos passageiros da meia-noite se surpreendeu ao vê-lo, e isso me levou a pensar que era apenas mais um daqueles disfarçados que nos domingos vendiam de tudo para as crianças nos parques. Mas a realidade me convenceu de que eu não podia duvidar, porque seu conjunto de cornos e suas barbas eram tão rústicos como os de um bode a ponto de sentir o cheiro desagradável de seu pelame ao passar por ele. [...] Na manhã seguinte eu já não sabia se na verdade tinha visto o fauno no bonde ou se tinha sido uma alucinação dominical. (MÁRQUEZ, 2003, p. 262, 263)
}

Volume 18

Número 40 


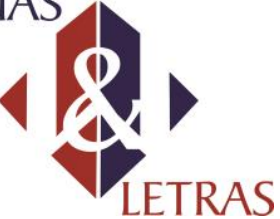

e-ISSN: 1981-4755

DOI: $10.5935 / 1981-4755.20170032$

autor/escritor/jornalista/ atividades intelectuais e atividades prosaicas do cotidiano, filho/marido.

Definir Viver para Contar como autobiográfica, apenas por que o autor é o mesmo, que tem seu nome na capa, seria uma definição superficial e limitante. O que torna o texto uma autoescrita é o seu aspecto híbrido que o define como uma representação não apenas dos fatos reais da vida do autor, mas também de sua reflexão crítica durante sua formação como escritor e fatos históricos recontados através do olhar de quem escreve, muitas vezes, fruto do imaginário.

Vimos que textos de cunho memorialísticos, como o de Santo Agostinho, apesar de não serem classificados como autobiografias, demonstras em sua forma de escrita, a busca por um autoconhecimento do autor, a mesma estrutura pode ser observada no texto de G. G. Márquez, quando o autor demonstra seu interesse por textos literários e reflete sobre a maneira como se iniciou como escritor.

Esto coincidía con mi determinación de aprender a construir una estructura al mismo tempo verosímil y fantástica, pero sin resquicios. Con modelos perfectos y esquivos, como Edipo rey, de Sófocles, cuyo protagonista investiga el asesinato de su padre y termina por descubrir que él mismo es el asesino; como 'La pata de mono', de W. W. Jacob, que es el cuento perfecto, donde todo cuanto sucede es casual ${ }^{13}$. (MÁRQUEZ, 2015, p.294)

A obsessão pela busca de uma narrativa perfeita o conduz a uma construção na qual o autor possa expressar, da mesma forma, que os clássicos que admira. Nessa busca, o autor cria o próprio personagem, que se transformou mais tarde, no autor consagrado e reconhecido mundialmente. "Muchas de las novelas que entonces leia y admiraba sólo me interesaban por sus enseñanzas técnicas. Es decir: por su carpintería secreta." ${ }^{14}$ (MÁRQUEZ, 2015, p. 297).

G. G. Márquez não está apenas escrevendo um texto autobiográfico para narrar fielmente sua vida, nem está totalmente desligado dos aspectos autobiográficos, voltando-se às escritas de si, mas fazendo um retrospecto de sua formação como autor,

\footnotetext{
${ }^{13}$ Aquilo coincidiu com minha determinação de aprender a construir uma estrutura ao mesmo tempo verossímil e fantástica, mas sem resquícios. Com modelos perfeitos e esquivos, como Édipo rei, de Sófocles, cujo protagonista investiga o assassinato de seu pai e termina por descobrir que ele próprio é o assassino; como 'A pata do macaco', de W. W. Jacob, que é o perfeito, onde tudo que acontece é casual (MÁRQUEZ, 2003, p.262).

${ }^{14}$ Muitos dos romances que eu lia e admirava naquele tempo só me interessavam por causa de suas lições técnicas. Quer dizer: pela sua carpintaria secreta. (MÁRQUEZ, 2003, p. 264)

Volume 18

Número 40
} 


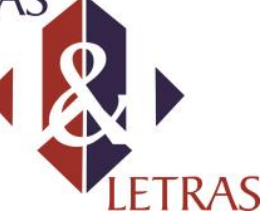

e-ISSN: 1981-4755

DOI: $10.5935 / 1981-4755.20170032$

na tentativa de entender como esse processo influenciou seu papel como escritor Latino Americano.

Ao construir a narrativa de Viver para Contar, constrói o seu próprio personagem, Gabriel García Márquez e nessa construção relata exatamente o que se propõe em sua epígrafe, um relato da sua vida, não totalmente real, mas ao mesmo tempo real para o autor que traz o nome na capa. O autor deixa claro em diversos momentos que essas são as suas lembranças: "En los años em que evoco estas memorias". ${ }^{15}$ (MÁRQUEZ, 2015, p.493). A fusão entre o real e o imaginário do autor é o que vai ser expresso durante toda a narrativa, potencializando a significação do texto híbrido. A obra revela em diferentes níveis a vida do autor.

O caráter híbrido e a diversidade dos modos de escrever constituem características apontadas por pesquisadores da literatura e pelos próprios escritores latino-americanos ao se referirem ao panorama literário contemporâneo. G. G. Márquez demostra em sua autoescrita, o quanto de sua própria vida está em sua obra, assim nenhuma parte do híbrido autor que é G. G. Márquez pode ficar de fora na análise da obra.

O recurso ao traço autobiográfico remete à memória, aos usos do discurso histórico, à mistura de gêneros, tais como o ensaio, a crítica e o romance, o cruzamento da literatura com as artes contemporâneas, a experiência do exílio, do deslocamento e da crise da identificação com a língua e com a cultura de origem, assim como as complexas relações entre escritura e política, configuram um conjunto rico de questões para se pensar, a partir da obra de G. G. Márquez.

Viver para contar (2003) é uma viagem de volta à casa de sua infância. É nessa viagem que o autor decide que se tornará um escritor. Viver para contar relata o início da vida do autor até o momento que é exilado da Colômbia. A obra seria o marco inicial de um conjunto de dois volumes sobre a sua vida, mas, infelizmente, G. G. Márquez nunca chegou a escrever o segundo volume de sua autobiografia, contudo, muitos elementos autobiográficos vão aparecer fundidos em outras narrativas, a exemplo da obra Cheiro de Goiaba (2014), cujo início da narrativa remonta à casa da infância, rememorada a partir dos 30 anos do personagem. Trata-se de um regresso para a cidade de Aracataca, até o nascimento, redobrando-se depois até a saída da Colômbia.

Em sua autobiografia G. G. Márquez relata que a primeira vez que teve consciência de que se tornaria um escritor foi na concepção da ideia do texto para $L a$

\footnotetext{
${ }^{15}$ Nos anos em que evoco essas memórias. (MÁRQUEZ, 2003, p. 444)

Volume 18

Número 40
} 


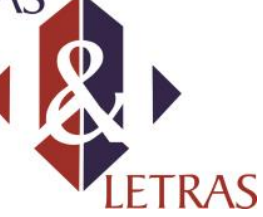

e-ISSN: 1981-4755

DOI: $10.5935 / 1981-4755.20170032$

Casa. O estilo de escritor que desejava se tornar já existia desde que leu Kafka. "Foi Kafka que, em alemão, contava as coisas da mesma maneira que minha avó. Quando li aos dezessete anos A metamorfose, descobri que ia ser escritor”. (MÁRQUEZ, 2014, p. 45). O estilo de narrativa que desejava adotar já estava definido desde a adolescência, mas é durante a viagem à Aracataca que a temática da escrita vai tomar forma.

Apresenta-se, aí, a primeira concepção de um espaço de escrita que vai acompanhar o autor em diversas narrativas, o espaço da casa como uma relação direta da história e vida dos personagens. A obra de G. G. Márquez se aproxima do espaço da casa não apenas no texto autobiográfico, mas no conjunto de sua obra.

$\mathrm{Na}$ narrativa, o autor revela sua opção por ser um escritor ficcional. Esta obra funda o projeto do livro La Casa, obra que nunca chegou a ser finalizada, mas que demonstra ser um espaço crucial na obra de G. G. Márquez, uma vez que o espaço da casa é recorrente em diferentes obras do autor.

Viver para contar articula-se ao livro Cheiro de Goiaba (2014), onde se observa a memória da casa da família relacionada à construção da autobiográfica.

A obra de G. G. Márquez nos mostra um autor que exaustivamente pensa em sua situação como escritor latino-americano. Podemos observar desde o inicio de Viver para contar, que não se trata de apenas um texto que relata a sua existência, mas que analisa sua construção como autor/critíco/colombiano. O mesmo pensamento crítico é observado em Cheiro de Goiaba, onde o autor concede uma série de entrevistas a Plínio Apuleyo Mendoza, falando sobre sua vida, profissão, família, influências e construção de sua obra. Nessas conversas o autor revela como se dá a criação de suas narrativas, influências literárias e como suas memórias tem um papel direto nessas composições.

- E qual foi a imagem visual que serviu de ponto de partida para Cem anos de solidão?

- Um velho que leva um menino para conhecer o gelo, exibido como curiosidade de circo.

— Era o seu avô, o Coronel Márquez?

- Sim.

- O fato é tirado da realidade?

- Não diretamente, mas está inspirado nela. (MÁRQUEZ, 2014, p. 39, 40)

Observa-se na obra do autor, o texto autobiográfico historiografado, uma mistura entre as suas lembranças com a construção quase mítica de sua história familiar e posteriormente com a história colombiana e o contexto latino americano. 


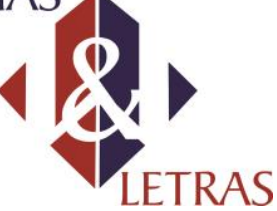

e-ISSN: 1981-4755

DOI: $10.5935 / 1981-4755.20170032$

Essas questões permeiam o cenário atual da literatura produzida na América Latina e revelam espaços de memória, que funcionam, muitas vezes como metáforas, a exemplo da casa na obra de G. G. Márquez. A metáfora da casa aparece com recorrência na obra do autor, sobretudo, nas narrativas autobiográficas.

Em Cheiro de Goiaba, G. G. Márquez descreve que no início de sua carreira, escrever era como um reflexo: "era um ato alvoroçado, quase irresponsável" (MARQUEZ, 2014, p. 39), mas com o passar do tempo, a expressão se torna cada vez mais difícil. "O que acontece é simples é que vai aumentando o senso de responsabilidade. Tem-se a impressão de que cada letra que se escreve agora tem uma ressonância maior, afeta muito mais gente" (MARQUEZ, 2014, p. 40). O instrumento continua o mesmo, a escrita ainda é a forma escolhida para comunicar, mas o modo de utilizar o instrumento mudou na percepção do autor.

\section{CONSIDERAÇÕES FINAIS}

Em Viver para Contar e em Cheiro de Goiaba temos uma narrativa de uma pessoa real em retrospectiva de sua própria existência, mas este sujeito é um dos grandes autores do século vinte. Que passa a pensar sua existência e como deseja que ela seja retratada da mesma forma que constrói um personagem de sua obra ficcional. Deparamo-nos com um autor que trabalha com uma escrita híbrida entre o ficcional, o histórico e o memorialístico e narra os eventos de sua vida como uma construção narrativa ficcional.

G. G. Márquez revela uma construção de fatos que apenas um autor tal poderia realizar, seu texto demonstra não apenas a trajetória como escritor, mas, os caminhos que o levaram para a construção da própria obra. Viver para contar seria a primeira parte de uma produção de dois livros que o autor nunca chegou a terminar. Mas, exatamente, a interrupção do livro torna a obra única, como um rompimento/rasura na linha de memória que se esperava de uma autobiografia, tornando o texto original, também, por este aspecto do inacabado.

\section{REFERÊNCIAS}

AgOSTINHO, Santo. Confissões. Trad.: J. Oliveira Santos e A. Ambrósio de Pina. $4^{\text {a }}$ ed. São Paulo: Nova Cultural, 1987.

CARPEAUX, Otto. Apresentação, em CARPENTIER, Alejo. O reino deste mundo. Trad.: João Olavo Saldanha. Rio de Janeiro: Ed. Civilização Brasileira, 1985.

Volume 18

Número 40 


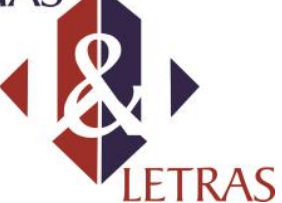

KLINGER, Diana. Escritas de si, escritas do outro: o retorno do autor e a virada etnográfica. $2^{\mathrm{a}}$ ed. Rio de Janeiro: 7Letras, 2012.

LEJEUNE, Philippe. O pacto Autobiográfico. Trad.: Jovita Maria Gerheim Noronha, Maria Inês Coimbra Guedes. 2a ed. Belo Horizonte: Editora UFMG, 2014.

GARCÍA MÁRQUEZ, Gabriel. Cem Anos de Solidão. Trad.: Eliane Zagury. Rio de Janeiro: O Globo; São Paulo: Folha de São Paulo, 2003.

Cheiro de Goiaba: conversas com Plinio Apuleyo Mendoza. Trad.: Eliane

Zagury. $7^{\text {a }}$ ed. Rio de Janeiro: Record, 2014.

Crónica de una muerte anunciada. Sexta edicíon. España: Penguin Random

House. Grupo Editorial, S.A.U., 2015.

Viver Para Contar. Trad.: Eric Nepomuceno. Rio de Janeiro: Record, 2003.

Vivir Para Contarla. Sexta edicíon. España: Penguin Random House Grupo

Editorial, S.A.U., 2015.

TARKOVISKY. Andreaei Arsensevich. Esculpir o Tempo. $2^{\text {a }}$ edição, São Paulo:

Martins fontes, 1998.

Data de recebimento: 01/08/2017

Data de aprovação: 31/08/2017 